\title{
LA PROTECCIÓN PENAL DE LAS UNIONES DE HECHO EN LATINOAMÉRICA*
}

\author{
THE CRIMINAL LAW PROTECTION \\ FOR THE DE FACTO MARITAL \\ UNIONS IN LATIN AMERICA
}

\author{
Raúl Santacruz-López** \\ Jinyola Blanco-Rodríguez**** \\ Fecha de recepción: 1 de julio de 2014 \\ Fecha de aceptación: 11 de septiembre de 2014 \\ Disponible en línea: 30 de junio de 2015
}

\section{Para citar este artículo/To cite this article}

\author{
Santacruz-López, Raúl \& Blanco-Rodríguez, Jinyola, La protección penal \\ de las uniones de hecho en Latinoamérica, 130 Vniversitas, 273-308 (2015). \\ http://dx.doi.org/10.11144/Javeriana.vj130.ppuh \\ doi:10.11144/Javeriana.vj130.ppuh
}

* Este artículo es un resultado del proyecto de investigación que sobre La unión de hecho en Latinoamérica desarrollaron las Facultades de Derecho de la Universidad de Buenos Aires (Argentina) y de la Universidad Antonio Nariño, sede Bogotá (Colombia).

This article is a result of the research project on De facto marital union in Latin America, developed by the Law Schools of the University of Buenos Aires (Argentina) and Universidad Antonio Nariño, Bogotá (Colombia).

** Doctorando en Derechos Humanos y Libertades Fundamentales, Universidad de Zaragoza, España. Juez penal del Circuito con función de conocimiento de Bogotá; docente investigador, Facultad de Derecho, Universidad Antonio Nariño, sede Bogotá y líder del grupo de investigación Iustitia, categorizado en Colciencias. Contacto: raul.santacruz@uan.edu.co

*** Doctoranda en Derecho de Familia y de la Persona, Universidad de Zaragoza, España. Directora de la Maestría en Derecho de Familia, Universidad Antonio Nariño e investigadora principal del proyecto dentro del cual se produjo el presente artículo. Contacto: jinyola. blanco@uan.edu.co 


\section{RESUMEN}

El reconocimiento de las uniones de hecho - heterosexuales y homosexuales-, como formas alternativas de familia establecidas mediante vínculos naturales, constituye una irrefutable realidad para la sociedad latinoamericana actual. Los efectos jurídicos de este hecho son incuestionables, como también lo es la consecuencia de haber generado la necesidad de protegerlas en materia penal. Para el estudio de este fenómeno, se realizó una investigación normativa internacional, desarrollada bajo la estrategia cualitativa de análisis de contenido de los documentos pertinentes, que finalmente produjo este artículo como uno de sus resultados. Como se demostrará más adelante, la protección de estas uniones convivenciales es generalizada, aunque es claro que en los países a los que se limitó este trabajo no rige el mismo nivel de amparo y que en algunos no se las protege, principalmente porque la misma legislación penal vigente se erige en una barrera infranqueable para ello. En consecuencia, se requieren cambios radicales en esta materia y políticas públicas que garanticen el ejercicio de los derechos de esta forma de familias y de sus integrantes.

Palabras clave: unión marital de hecho; parejas de hecho; protección penal de las uniones de hecho; agravación y atenuación punitivas; prevención del delito 


\section{ABSTRACT}

Acknowledging common law marriage -both heterosexual and homosexual- as an alternate type of family, established by means of natural relationships, is an irrefutable reality for the current Latin American society. The legal effects of this fact are unquestionable, as it is the consequence of the generation of the need to protect them in legal matters. We performed a research on international regulations to study this phenomenon, which was developed under the qualitative strategy of a content analysis of the relevant documents that, in the end, would lead to the writing of this article as one of the results. As evidenced in a further section, the protection of these domestic partnerships is commonplace, although it is evident that the level of protection is not the same across the countries studied within this work. Some countries provide no protection at all, mainly because their existing legislation constitutes an impassable barrier for it. As a consequence, radical changes are required in this matter and regarding public policies, so they guarantee the exercise of the rights of this type of families and their members.

Keywords: common law marriage; common law partners; legal protection of common law marriages; penal aggravation and attenuation; crime prevention

\section{SUMARIO}

InTRODUCCIÓN.- I. Resultados. LA FAMILIA.- II. LA PROTECCIÓN PENAL DE Las Uniones de heCho en Latinoamérica. A. Colombia.- $B$. Argentina.- $C$. Bolivia.- D. Brasil.- E. Chile.- F. Ecuador.- G. Panamá.- H. Paraguay.- I. Perú.- J. Uruguay.- K. Venezuela.- Conclusiones.- Bibliografía. 


\section{INTRODUCCIÓN}

En los Estados latinoamericanos, caracterizados por la marcada influencia de las legislaciones romanistas heredadas de los países conquistadores provenientes de la Península Ibérica, se observa que el fenómeno de protección penal de las uniones maritales de hecho o simplemente uniones de hecho, no es de vieja data. Su desarrollo e implementación han corrido en forma paralela con el amparo que, poco a poco, se les ha ido otorgando en la legislación civil, sin ser anterior a la segunda mitad del siglo XX.

Lo expresado tiene su explicación en la enorme influencia que sobre todas esas culturas tuvo la religión católica. La consideración de que los hijos habidos fuera del matrimonio ("ilegítimos", "bastardos", "naturales" o "de dañado y punible ayuntamiento") tenían una categoría inferior a la de los matrimoniales ("legítimos"), es una clara muestra de la tremenda discriminación clerical que imperaba y que solo concebía como familia a aquella que había sido autorizada por sus ritos.

Así, el concepto de familia adoptado por el derecho positivo estuvo restringido, en toda Latinoamérica, desde la época de la Conquista hasta el presente siglo, únicamente a aquella primera célula de la sociedad constituida por el matrimonio entre un hombre y una mujer y los hijos procreados por ellos. Quedó por fuera cualquier otra forma de integración afectiva entre parejas, motivo por el cual las de hecho y las de las personas del mismo sexo fueron excluidas de su amparo. En la actualidad, tal concepto ha cambiado y ahora también comprende, en algunos de estos países, las uniones de hecho entre personas de diferente sexo e incluso a las homosexuales, con lo cual se ha logrado que la protección familiar, procurada por el derecho penal, se adecúe a estas nuevas situaciones.

El contexto aquí planteado no puede ser ignorado por ninguna persona, cualquiera que sea su fundamento jurídico, social, económico, político, ético, filosófico o religioso y hasta biológico, porque con ello estaría desconociendo un hecho evidente e incuestionable, imbricado en la realidad actual: el de la existencia de formas alternativas de integración entre parejas, cuyas relaciones son la causa de muchas situaciones de conflicto, complejas y con efectos jurídicos, que deben ser objeto de regulación legal y esencialmente 
penal, mediante políticas criminales acordes con sus particulares características.

\section{RESULTADOS. LA FAMILIA}

Es indudable que la familia ha sido considerada como una institución fundamental en todas las sociedades, lo que se refleja en la protección que se le brinda en los instrumentos internacionales: la Declaración Universal de los Derechos Humanos, en su artículo 16.1, reconoce el derecho de los hombres y las mujeres, a partir de la edad núbil y sin restricción alguna por motivos de raza, nacionalidad o religión, a casarse y fundar una familia, pudiendo disfrutar de iguales derechos en cuanto al matrimonio, durante el matrimonio y en caso de disolución del matrimonio; en el punto 2 del mismo artículo se proclama que este solo podrá contraerse mediante el libre y pleno consentimiento de los esposos, a la par que en el numeral 3 se identifica a la familia como el elemento natural y fundamental de la sociedad, con derecho a la protección por parte de la sociedad y del Estado․ El Pacto Internacional de Derechos Civiles y Políticos, art. 23, recoge lo anterior imponiéndoles a los Estados Partes la obligación de tomar las medidas apropiadas para asegurar la igualdad de los esposos y la protección de los hijos². La Convención Americana sobre Derechos Humanos también se refiere a la familia y en especial a su protección, artículo 17, admitiendo: "el derecho del hombre y la mujer a contraer matrimonio y a fundar una familia si tienen la edad y las condiciones requeridas para ello por las leyes internas, en la medida en que estas no afecten al principio de no discriminación establecido en esta Convención", con lo que aglutina las manifestaciones de los dos instrumentos inicialmente mencionados y agrega que la ley debe reconocer iguales derechos a los hijos habidos dentro y fuera del matrimonio ${ }^{3}$.

1 Organización de Naciones Unidas, Declaración Universal de Derechos Humanos, adoptada y proclamada por la Asamblea General, Resolución 217 A (III), 10 de diciembre de 1948, Artículos 16.1, 16.2 y 16.3. Disponible en: http://www.acnur.org/t3/fileadmin/Documentos/BDL/2001/0013. pdf? view $=1$

2 Organización de Naciones Unidas, Pacto Internacional de Derechos Civiles y Políticos, adoptado y proclamado por la Asamblea General, Resolución 2200 A (XXI), 16 de diciembre de 1966, Artículo 23. Disponible en: http://www.ohchr.org/SP/ProfessionalInterest/Pages/CCPR.aspx

3 Organización de Estados Americanos, OEA, Convención Americana sobre Derechos Humanos, San José de Costa Rica, 22 de noviembre de 1969, Artículo 17. Disponible en: http://www.oas.org/ dil/esp/tratados_b-32_convencion_americana_sobre_derechos_humanos.htm 
En la vigente Constitución Política de Colombia de 1991, refiere que la familia "es el núcleo fundamental de la sociedad. Se constituye por vínculos naturales o jurídicos, por la decisión libre de un hombre y una mujer de contraer matrimonio o por la voluntad responsable de conformarla"4. La familia queda así limitada a las de naturaleza nuclear y heterosexual, aunque con el inevitable reconocimiento de la unión marital de hecho como una forma de familia producida por "vínculos naturales".

La Constitución de la Nación Argentina, cuya modificación más reciente fue en 1994, protege en forma general a la familia, sin incorporar una definición de ella. Textualmente, dice: “(...) En especial, la ley establecerá: ...la protección integral de la familia; la defensa del bien de familia; la compensación económica familiar y el acceso a una vivienda digna"s.

La Constitución Política del Estado, promulgada en Bolivia en 2009, consagra expresamente que "Las uniones libres o de hecho que reúnan condiciones de estabilidad y singularidad, y sean mantenidas entre una mujer y un hombre sin impedimento legal, producirán los mismos efectos que el matrimonio civil, tanto en las relaciones personales y patrimoniales de los convivientes como en lo que respecta a las hijas e hijos adoptados o nacidos de aquellas"6. Y agrega más adelante: "Se garantiza a las mujeres y a los hombres el ejercicio de sus derechos sexuales y sus derechos reproductivos"7.

La Constitución de la República Federativa del Brasil, emitida en 1988, "reconoce la unión estable entre el hombre y la mujer como entidad familiar", aunque también dispone que la ley debe "facilitar su conversión en matrimonio"s.

4 Constitución Política de Colombia [Const], 7 de julio de 1991, Art 42. Disponible en: http://www. alcaldiabogota.gov.co/sisjur/normas/Norma1.jsp?i=4125

5 Constitución de la Nación Argentina [Const], 22 de agosto de 1994, Art. 14 Bis. Disponible en: http:// infoleg.mecon.gov.ar/infolegInternet/anexos/0-4999/804/norma.htm, http://www.constitution.org/ cons/argentin.htm

6 Constitución Política del Estado Plurinacional de Bolivia [Const], 7 de febrero de 2009, Art. 63.II. Disponible en: http://www.ncpe.org.bo/

7 Constitución Política del Estado Plurinacional de Bolivia [Const], 7 de febrero de 2009, Art. 66. Disponible en: http://www.ncpe.org.bo/

8 Constitución de la República Federativa de Brasil [Const], 5 de octubre de 1988, Art. 226, 3. Disponible en: http://pdba.georgetown.edu/Constitutions/Brazil/esp88.html\#mozTocId757336, texto en portugués http://www.wipo.int/edocs/lexdocs/laws/pt/br/br159pt.pdf, http://www.planalto.gov. br/ccivil_03/constituicao/constituicao.htm 
La Constitución Política de la República de Chile, con las modificaciones de 2005 y actualizada mediante Ley 20748 del 3 de mayo de 2014, igualmente ampara a la familia en forma general, reconociéndola como el "núcleo fundamental de la sociedad" y estableciendo como un deber del Estado el de darle protección y propender por su fortalecimiento, pero sin incorporar una definición de ella ${ }^{9}$.

La Constitución de la República del Ecuador, promulgada en 2008, expresa su reconocimiento a la familia en sus diversos tipos, admite su constitución por vínculos jurídicos y especifica que "el matrimonio es la unión entre hombre y mujer"10. No obstante, en relación con la unión de hecho, declara:

Art. 68. La unión estable y monogámica entre dos personas libres de vínculo matrimonial que formen un hogar de hecho, por el lapso y bajo las condiciones y circunstancias que señala la ley, generará los mismos derechos y obligaciones que tienen las familias constituidas mediante matrimonio.

La adopción corresponderá solo a parejas de distinto sexo.

La Constitución Política de la República de Panamá, cuyo texto único más reciente data de 2004, identifica el matrimonio como el fundamento legal de la familia ${ }^{11}$, aunque también acepta que la unión de hecho entre personas de distinto sexo es integradora de una familia, denominándola "matrimonio de hecho"l2.

La Constitución Política de la República de Paraguay, de 1992, incluye en el concepto de familia "la unión estable del hombre y la mujer, a los hijos y a la comunidad que se constituya con cualquiera de los progenitores y sus descendientes"13 y especifica que las "uniones de hecho entre el hombre y la mujer, sin impedimentos legales para contraer matrimonio, que reúnan las condiciones de

9 Constitución Política de la República de Chile [Const], 11 de septiembre de 1980, Art. 1. Disponible en: http://www.senado.cl/constitucion-politica-capitulo-i-bases-de-la-institucionalidad/prontus_senado/2012-01-16/093048.html

10 Constitución de la República del Ecuador [Const], 20 de octubre de 2008, Art. 67. Disponible en: http://pdba.georgetown.edu/Parties/Ecuador/Leyes/constitucion.pdf

11 Constitución Política de la República de Panamá [Const], 15 de noviembre de 2004, Art. 57. Disponible en: http://www.organojudicial.gob.pa/cendoj/cendojfields/constitucion-politica/

12 Constitución Política de la República de Panamá [Const], 15 de noviembre de 2004, Art. 58. Disponible en: http://www.organojudicial.gob.pa/cendoj/cendojfields/constitucion-politica/

13 Constitución de la República de Paraguay [Const], 20 de junio de 1992, Art. 49. Disponible en: http://www.bacn.gov.py/constitucion-nacional-de-la-republica-del-paraguay.php 
estabilidad y singularidad, producen efectos similares al matrimonio, dentro de las condiciones que establezca la ley"14.

La Constitución Política del Perú, de 1993, cuya más reciente disposición transitoria se incorporó en 2009, brinda su amparo a la familia y promueve el matrimonio como "institutos naturales y fundamentales de la sociedad"15. Así mismo, acepta la comunidad de bienes sujeta al régimen de la sociedad de gananciales, en lo que se ha conocido como "concubinato" y que define como "la unión estable de un varón y una mujer, libres de impedimento matrimonial, que forman un hogar de hecho"16.

La Constitución Política de la República Oriental del Uruguay de $1997^{17}$, hasta la reforma de 2004, no incorpora una definición de la institución familiar y solo indica que velará por su estabilidad moral y material ${ }^{18}$.

Por último, la Constitución de la República Bolivariana de Venezuela, aprobada en 1999, protege y reconoce a la familia como "asociación natural de la sociedad"19 y, al igual que en el matrimonio entre un hombre y una mujer, consagra que las uniones estables de hecho entre los mismos, producirán iguales efectos que el matrimonio ${ }^{20}$.

En los países latinoamericanos materia de este proceso investigativo, la familia constituye uno de los bienes jurídicos con la más expresa protección por medio de la ley penal, lo cual resulta coherente con la consideración, en todos ellos, de tratarse de la primera célula o de la base fundamental de la sociedad. Lo que varía en sus Cartas Políticas y leyes internas es el alcance que se le otorga al concepto de familia, pues aunque la mayoría cobija en

14 Constitución de la República de Paraguay [Const], 20 de junio de 1992, Art. 51. Disponible en: http://www.bacn.gov.py/constitucion-nacional-de-la-republica-del-paraguay.php

15 Constitución Política del Perú [Const], 29 de diciembre de 1993, Art. 4. Disponible en: http://www4. congreso.gob.pe/ntley/Imagenes/Constitu/Cons1993.pdf

16 Constitución Política del Perú [Const], 29 de diciembre de 1993, Art. 5. Disponible en: http://www4. congreso.gob.pe/ntley/Imagenes/Constitu/Cons1993.pdf

17 En realidad, se trata de la "Constitución 1967 con las modificaciones plebiscitadas el 26 de noviembre de 1989, el 26 de noviembre de 1994, el 8 de diciembre de 1996 y el 31 de octubre de 2004". http://www.parlamento.gub.uy/constituciones/const004.htm

18 Constitución Política de la República Oriental del Uruguay [Const], 14 de enero de 1997, Art. 40. Disponible en: http://www.parlamento.gub.uy/constituciones/const004.htm

19 Constitución de la República Bolivariana de Venezuela [Const], 20 de diciembre de 1999, Art. 75. Disponible en: http://www.cne.gov.ve/web/normativa_electoral/constitucion/indice.php

20 Constitución de la República Bolivariana de Venezuela [Const], 20 de diciembre de 1999, Art. 77. Disponible en: http://www.cne.gov.ve/web/normativa_electoral/constitucion/indice.php 
su definición la unión de hecho o libre (Bolivia, Brasil, Colombia, Ecuador, Panamá, Paraguay, Perú y Venezuela) y en algunos casos llega a equiparla al concepto de matrimonio, no en todos los estatutos penales se consagra su protección.

\section{LA PROTECCIÓN PENAL DE LAS UNIONES DE HECHO EN LATINOAMÉRICA}

\section{A. Colombia}

Cumpliendo su función represora, el estatuto punitivo protege el bien jurídico de la familia mediante la sanción de las conductas que atentan contra su armonía o unidad, protección que comprende a las uniones de hecho, tanto heterosexuales como homosexuales, de acuerdo con los parámetros de no discriminación fijados por la Corte Constitucional.

Bajo el título genérico de Delitos contra la familia son definidos delitos como la violencia intrafamiliar, que sanciona con pena de prisión al que maltrate física o psicológicamente a cualquier miembro de su núcleo familiar, concepto este equivalente a los de unidad familiar, grupo familiar o unidad doméstica y con los alcances reconocidos en la Sentencia C-029-09 respecto de los compañeros permanentes del mismo sexo ${ }^{21}$. De la misma manera son reprimidos punibles como el ejercicio arbitrario de la custodia de hijo menor de edad y el maltrato mediante restricción a la libertad física, en el que se define el ingrediente normativo grupo familiar, que limita su aplicación al mismo artículo:

...se entenderá que el grupo familiar comprende los cónyuges o compañeros permanentes; el padre y la madre de familia, aunque no convivan en un mismo lugar; los ascendientes o descendientes de los anteriores y los hijos adoptivos; todas las demás personas que de manera permanente se hallaren integradas a

21 Corte Constitucional de Colombia, Sentencia C-029-09, 28 de enero de 2009, magistrado ponente Rodrigo Escobar-Gil. Disponible en: http://www.corteconstitucional.gov.co/ relatoria/2009/c-029-09.htm. La expresión "compañeros permanentes" utilizada frecuentemente en el Código Penal fue declarada condicionalmente exequible, "en el entendido de que, para los efectos de las medidas administrativas de protección previstas en esa ley, la misma también se aplica, en igualdad de condiciones, a los integrantes de las familias del mismo sexo". 
la unidad doméstica. La afinidad será derivada de cualquier forma de matrimonio, unión libre ${ }^{22}$ (negrilla fuera de texto).

También se incluyen como vulneradores del bien jurídico de la familia, los delitos de inasistencia alimentaria y malversación y dilapidación de bienes de familiares ejecutados, entre otros, respecto del compañero o compañera permanente, entendidos estos como el hombre y la mujer integrantes de la unión marital de hecho ${ }^{23}$ durante un lapso no inferior a dos años, según lo establece la Ley 54 de $1990^{24}$.

En otros capítulos del Código Penal y con referencia a otros bienes jurídicos, también se otorga protección a estas formas de familia. Uno de ellos es el delito de amenazas a testigo ${ }^{25}$, ubicado entre los referidos al bien jurídico de la eficaz y recta impartición de justicia, que reprime esta acción cuando se realiza sobre una persona testigo de un delito o en contra de su compañero o compañera permanente, entre otros, para que no actúe como tal o falte a la verdad. En otros tipos penales como la fraudulenta internación en asilo, clínica o establecimiento similar, que protege la autonomía personal y en el que se fija una pena especial, mayor a la prevista para las demás personas, para el responsable que "sea integrante de la familia de la víctima", surge la duda acerca de si se podría aplicar el concepto de familia a las uniones de hecho heterosexuales y homosexuales. Esto mismo podría decirse del delito de amenazas, que tutela el bien jurídico de la seguridad pública, cuando menciona a la "familia" y a "los familiares" como sujetos pasivos de tal punible.

Como circunstancia de menor punibilidad se consagra, en el artículo 55 del Código Penal, el actuar bajo la influencia de apre-

22 Código Penal Colombiano [CPC], Ley 599 de 2000, por la cual se expide el Código Penal, 24 de julio de 2000, 44097 Diario Oficial, 24 de julio de 2000. Parágrafo del artículo 230, adicionado por el artículo 32 de la Ley 1257 de 2008. Disponible en: http://www.alcaldiabogota.gov.co/sisjur/ normas/Norma1.jsp?i $=6388$

23 Ley 54 de 1990, por la cual se definen las uniones maritales de hecho y régimen patrimonial entre compañeros permanentes, 28 de diciembre de 1990, 39615 Diario Oficial, 31 de diciembre de 1990, Art. 1. Disponible en: http://www.alcaldiabogota.gov.co/sisjur/normas/Norma1.jsp?i=30896

24 Código Penal Colombiano [CPC], Ley 599 de 2000, por la cual se expide el Código Penal, 24 de julio de 2000, 44097 Diario Oficial, 24 de julio de 2000, parágrafo 1 del artículo 233 adicionado por el artículo 1 de la Ley 1181 de 31 de diciembre de 2007. Disponible en: http://www.alcaldiabogota. gov.co/sisjur/normas/Norma1.jsp?i=6388

25 Código Penal Colombiano [CPC], Ley 599 de 2000, por la cual se expide el Código Penal, 24 de julio de 2000, 44097 Diario Oficial, 24 de julio de 2000, art. 454A. Disponible en: http:// www.alcaldiabogota.gov.co/sisjur/normas/Norma1.jsp?i=6388 
miantes circunstancias personales o familiares en la ejecución de la conducta punible, haciendo menos gravosos los efectos del delito cuando es cometido en tales condiciones, con una implícita protección al grupo familiar y a los que actúan en su defensa. Otra demostración ostensible de protección al grupo familiar y específicamente a las uniones de hecho, se encuentra en la tipificación, como circunstancia de agravación punitiva, de la realización de la conducta punible sobre el compañero permanente, precisando que sus previsiones también comprenden a los integrantes de las parejas del mismo sexo, como lo determinó la Corte Constitucional en la sentencia C-029-09. Esta circunstancia se encuentra en delitos como homicidio, lesiones personales, secuestro extorsivo, tortura, constreñimiento ilegal, constreñimiento para delinquir, trata de personas, violencia intrafamiliar (del que se sustrajo el abuso sexual para reconocerle su carácter de delito independiente y concurrente) $)^{26}$ y muchos otros.

La anterior circunstancia de agravación también protege a los parientes, hasta el segundo grado de afinidad de aquellos a quienes se quiere perjudicar directamente por razón de sus calidades, entendiéndose la afinidad como derivada de cualquier forma de unión libre. Esto ocurre en el caso de "servidores públicos, comunicadores, defensores de derechos humanos, candidatos o aspirantes a cargos de elección popular, dirigentes o miembros de una organización sindical legalmente reconocida, políticos o religiosos, contra quienes hayan sido testigos de conductas punibles o disciplinarias, juez de paz, o contra cualquier otra persona por sus creencias u opiniones políticas o por motivo que implique alguna forma de discriminación o intolerancia" ${ }^{27}$, para la desaparición forzada. Lo mismo que ocurre cuando se trata de la compañera o compañero permanente de los ya mencionados y de sus parientes, en el delito de tortura.

Pero estas no son las únicas formas de protección para esta clase de familias: en la ley penal colombiana es posible encontrar,

26 Jinyola Blanco-Rodríguez \& Raúl Santacruz-López, La exclusión legal del abuso sexual entre cónyuges o compañeros permanentes como forma de violencia intrafamiliar, 118 Vniversitas, 141159 (enero-junio de 2009). Disponible en: http://www.redalyc.org/articulo.oa?id=82516351006

27 Código Penal Colombiano [CPC], Ley 599 de 2000, por la cual se expide el Código Penal, 24 de julio de 2000, 44097 Diario Oficial, 24 de julio de 2000, Art. 166, 5. Disponible en: http:// www.alcaldiabogota.gov.co/sisjur/normas/Norma1.jsp?i=6388 
en las conductas punibles por omisión, la posición de garante $^{28}$, dispositivo amplificador del tipo que hace responsable de un delito a todo aquel que teniendo el deber jurídico de impedir un resultado perteneciente a una descripción típica, no lo impide, estando en posibilidad de hacerlo. Esto también opera en las uniones de hecho porque entre sus integrantes existe una "estrecha comunidad de vida", condición expresamente reconocida como constitutiva de una posición de garantía.

En relación con los delitos culposos o con penas no privativas de la libertad, el juez puede llegar a prescindir de la imposición de la sanción cuando la considere no necesaria o cuando sus consecuencias han afectado exclusivamente al autor o, entre otros, a sus compañeras o compañeros permanentes ${ }^{29}$.

En materia de subrogados y beneficios judiciales, el nuevo Código Penitenciario y Carcelario modificó los artículos del Código Penal relacionados con ellos y con las medidas sustitutivas de la pena de prisión (detención y prisión domiciliaria, mecanismos de vigilancia electrónica, suspensión de la ejecución de la pena y libertad condicional), considerando solamente el arraigo familiar del sentenciado, salvo los casos en que pertenezca al grupo familiar de la víctima, recomendando revisar los antecedentes familiares para establecer la necesidad de la ejecución de la pena ${ }^{30}$. Excluyó los subrogados o beneficios judiciales o administrativos en las condenas por violencia intrafamiliar ${ }^{31}$.

Entre las penas privativas de otros derechos, que pueden ser principales o accesorias, se incluye la prohibición de aproximarse o de comunicarse con la víctima y/o con los integrantes de su grupo

28 Código Penal Colombiano [CPC], Ley 599 de 2000, por la cual se expide el Código Penal, 24 de julio de 2000, 44097 Diario Oficial, 24 de julio de 2000, Art. 25. Disponible en: http://www. alcaldiabogota.gov.co/sisjur/normas/Norma1.jsp?i=6388

29 Código Penal Colombiano [CPC], Ley 599 de 2000, por la cual se expide el Código Penal, 24 de julio de 2000, 44097 Diario Oficial, 24 de julio de 2000, Art. 34. Disponible en: http://www. alcaldiabogota.gov.co/sisjur/normas/Norma1.jsp?i=6388

30 Código Penitenciario y Carcelario de Colombia [CPyC], Ley 1709 de 20 de 2014, por medio de la cual se reforman algunos artículos de la ley 65 de 1993, de la ley 599 de 2000, de la ley 55 de 1985 y se dictan otras disposiciones, 20 de enero de 2014, 49039 Diario Oficial, 20 de enero de 2014, Arts. 22 a 30. Disponible en: http://www.icbf.gov.co/cargues/avance/docs/ley_1709_2014.htm

31 Código Penitenciario y Carcelario de Colombia [CPyC], Ley 1709 de 20 de 2014 , por medio de la cual se reforman algunos artículos de la ley 65 de 1993, de la ley 599 de 2000, de la ley 55 de 1985 y se dictan otras disposiciones, 20 de enero de 2014, 49039 Diario Oficial, 20 de enero de 2014, Art. 32 que modificó el art. 68A del Código Penal. Disponible en: http://www.icbf.gov.co/cargues/ avance/docs/ley_1709_2014.htm 
familiar ${ }^{32}$, lo que en el caso de delitos relacionados con la violencia intrafamiliar debe tener una duración igual al tiempo de la pena y hasta doce meses más ${ }^{33}$, previsiones con las que también son protegidas estas formas de familia, pues en su parágrafo se especifica que integran el grupo familiar los compañeros permanentes, y que para sus efectos, la afinidad será derivada de cualquier forma de matrimonio o unión libre.

La conducta punible genera la obligación de reparar los daños materiales y morales causados con su realización, apareciendo entre los titulares de la acción indemnizatoria los sucesores de los sujetos pasivos de los delitos y, entre estos, por decisión de la Corte Constitucional ${ }^{34}$, las compañeras y los compañeros permanentes, sin importar si la relación era heterosexual u homosexual, pues las dos tienen vocación hereditaria; se da así otra forma de protección para las familias constituidas por vínculos naturales.

\section{B. Argentina}

El Código Penal Argentino ${ }^{35}$ no protege expresamente el bien jurídico de la familia. No es posible, por esto, encontrar en su texto la descripción de comportamientos punibles que puedan afectarla directamente, debiendo deducirse que lo mismo ocurre con la unión de hecho. No se tipifican específicamente, como delitos autónomos, la violencia intrafamiliar o doméstica, ni el incesto, ni la inasistencia alimentaria. Sin embargo, la doctrina ha reconocido que el principio de protección integral a la familia, establecido por medio de "la Constitución Nacional (art.14 bis), numerosas constituciones provinciales y diversos tratados de derechos humanos de rango

32 Código Penal Colombiano [CPC], Ley 599 de 2000, por la cual se expide el Código Penal, 24 de julio de 2000, 44097 Diario Oficial, 24 de julio de 2000, Arts. 43, 10, 11 y parágrafo, 50, también art. 50. Disponible en: http://www.alcaldiabogota.gov.co/sisjur/normas/Normal. jsp?i=6388

33 Código Penal Colombiano [CPC], Ley 599 de 2000, por la cual se expide el Código Penal, 24 de julio de 2000, 44097 Diario Oficial, 24 de julio de 2000, Art. 51, inciso agregado por el artículo 25 de la Ley 1257 de 2008. Disponible en: http://www.alcaldiabogota.gov.co/sisjur/ normas/Norma1.jsp?i=6388

34 Corte Constitucional de Colombia, Sentencia C-238-12, 22 de marzo de 2012, magistrado ponente Gabriel Eduardo Mendoza-Martelo. Disponible en: http://www.corteconstitucional.gov.co/ relatoria/2012/c-238-12.htm

35 Código Penal de la Nación Argentina [CPA], Ley 11179 de 1921, 3 de noviembre de 1921. Disponible en: http://www.infoleg.gov.ar/infolegInternet/anexos/15000-19999/16546/texact.htm 
constitucional (art. 75 inc. 22), cuando garantizan el amparo de la familia aluden a la familia real, es decir, a la que funciona como tal en la sociedad, que puede tener su origen tanto en el matrimonio como en una convivencia no formalizada" ${ }^{36}$, con lo cual reconoce, como familia, a la unión de hecho.

En muy pocos casos, las relaciones familiares son tenidas en cuenta como circunstancia modificadora del quántum punitivo y menos aún aquellos en los que el vínculo de hecho afecta la dosificación de la pena. Entre los delitos contra la integridad sexual, por ejemplo, se estima como circunstancia de agravación la realización de la conducta punible por el cónyuge o por una persona conviviente $^{37}$, sin definir lo que debe entenderse por este, pero esta normativa destaca la mayor gravedad del comportamiento delictual sobre una persona que hace parte del entorno familiar del agresor, al sancionar a los que cooperen en la perpetración de delitos sexuales con la misma pena de los autores ${ }^{38}$. Otro tanto ocurre con los delitos contra la libertad individual, en los que se eleva la pena cuando la acción se realiza en la persona del cónyuge o conviviente ${ }^{39}$ y en el de extorsión ${ }^{40}$.

Llama la atención que para las acciones privadas solo se tomen en cuenta aquellas circunstancias que nacen del incumplimiento a los deberes de asistencia familiar cuando la víctima es el cónyuge, dejando por fuera a los convivientes (compañeros permanentes) ${ }^{41}$, al igual que no se encontró en el Código Penal Argentino una medida o instituto dirigido a evitar la realización de delitos en los que la potencial víctima pudiera ser el conviviente.

36 Cecilia Grosman \& María Alejandra Guillot, Derecho del conviviente a la afiliación de su pareja estable a una obra social, Diario La Ley, 3 (24 de febrero de 2005). Disponible en: http://www. aabioetica.org/juris/baxo5.htm

37 Código Penal de la Nación Argentina [CPA], Ley 11179 de 1921, 3 de noviembre de 1921, Arts. 125 inc. 3, 126, 2 y 127, 2. Disponible en: http://www.infoleg.gov.ar/infolegInternet/anexos/15000-19999/16546/texact.htm

38 Código Penal de la Nación Argentina [CPA], Ley 11179 de 1921, 3 de noviembre de 1921, Art. 133. Disponible en: http://www.infoleg.gov.ar/infolegInternet/anexos/15000-19999/16546/texact.htm

39 Código Penal de la Nación Argentina [CPA], Ley 11179 de 1921, 3 de noviembre de 1921, Art. 142 bis, 2 y 145 ter., 6. Disponible en: http://www.infoleg.gov.ar/infolegInternet/anexos/15000-19999/16546/ texact.htm

40 Código Penal de la Nación Argentina [CPA], Ley 11179 de 1921, 3 de noviembre de 1921, Art. 170, 2. Disponible en: http://www.infoleg.gov.ar/infolegInternet/anexos/15000-19999/16546/texact.htm

41 Código Penal de la Nación Argentina [CPA], Ley 11179 de 1921, 3 de noviembre de 1921, Art. 73, 4. Disponible en: http://www.infoleg.gov.ar/infolegInternet/anexos/15000-19999/16546/texact.htm 
En el Código Procesal Penal ${ }^{42}$, en cambio, en el procesamiento sin detención preventiva, se incluye como medida cautelar la facultad que se otorga al juez para disponer la exclusión del procesado del hogar cuando se proceda por delitos cometidos dentro de un grupo familiar conviviente, aunque estuviese constituido por uniones de hecho, y las circunstancias del caso hicieren presumir fundadamente que pueden repetirse ${ }^{43}$.

\section{Bolivia}

El Código Penal Boliviano ${ }^{44}$ dedica un título a los Delitos contra la Familia, refiriendo sus dos capítulos a los delitos contra el matrimonio y el estado civil y contra los deberes de asistencia familiar. En ellos reprime el abandono de familia, que se realiza cuando el sujeto agente se sustrae de cumplir sus obligaciones de sustento, habitación, vestido, educación y asistencia inherentes a la autoridad de los padres, tutela o condición de cónyuge o conviviente ${ }^{45}$; y el de atenuación por causa de honor ${ }^{46}$, cuando para salvar su propia honra o la de su mujer, realiza una conducta de alteración o sustitución del estado civil $^{47}$, al hacer insertar hechos falsos en el registro civil de nacimientos que alteren el estado civil o el orden de un recién nacido (numeral 2) y cuando mediante ocultación, sustitución o exposición... dejare a un recién nacido sin estado civil, tomare incierto o alterare el que le corresponde (numeral 3).

Como la Constitución equipara las uniones de hecho al matrimonio civil, el amparo que se les brinda para efectos de la indemnización

42 Código Procesal Penal Argentino [CPP], Ley 23984 de 1991, 4 de septiembre de 1991. Disponible en: http://www.infoleg.gov.ar/infolegInternet/anexos/0-4999/383/texact.htm

43 Código Procesal Penal Argentino [CPP], Ley 23984 de 1991, 4 de septiembre de 1991, Art. 310. Disponible en: http://www.infoleg.gov.ar/infolegInternet/anexos/0-4999/383/texact.htm

44 Código Penal Boliviano [CPB], Ley 1768 de 1997, 10 de marzo de 1997. Disponible en: http://iccdb. webfactional.com/documents/implementations/pdf/Bolivia-Codigo_Penale_y_Procedimento_Penal.pdf, http://www.wipo.int/wipolex/es/text.jsp?file_id=125360

45 Código Penal Boliviano [CPB], Ley 1768 de 1997, 10 de marzo de 1997, Art. 248. Disponible en: http://iccdb.webfactional.com/documents/implementations/pdf/Bolivia-Codigo_Penale_y_Procedimento_Penal.pdf, http://www.wipo.int/wipolex/es/text.jsp?file_id=125360

46 Código Penal Boliviano [CPB], Ley 1768 de 1997, 10 de marzo de 1997, Art. 245. Disponible en: http://iccdb.webfactional.com/documents/implementations/pdf/Bolivia-Codigo_Penale_y_Procedimento_Penal.pdf, http://www.wipo.int/wipolex/es/text.jsp?file_id=125360

47 Código Penal Boliviano [CPB], Ley 1768 de 1997, 10 de marzo de 1997, Art. 244. Disponible en: http://iccdb.webfactional.com/documents/implementations/pdf/Bolivia-Codigo_Penale_y_Procedimento_Penal.pdf, http://www.wipo.int/wipolex/es/text.jsp?file_id=125360 
de todo perjuicio causado a la víctima ${ }^{48}$, también las comprende, así como para la pena de multa $^{49}$, para la distribución del producto del trabajo carcelario ${ }^{50}$ y para los efectos de asistencia social ${ }^{51} \mathrm{e}$ internamiento ${ }^{52}$.

En el estatuto penal boliviano, el delito de homicidio adquiere la connotación agravada de asesinato, cuando se ejecuta contra "sus descendientes o cónyuge o conviviente, a sabiendas de que lo son" 53 , circunstancia que también agrava el delito de homicidio por emoción violenta ${ }^{54}$. Pero asimismo, hay lugar a la exención de pena, sin perjuicio de la acción civil, en los delitos de hurto, robo, extorsión, estafa, estelionato, apropiación indebida y daño, cuando son causados, recíprocamente, por "los cónyuges no divorciados, los no separados legalmente o los convivientes" $" 55$.

El Código de Procedimiento Penal ${ }^{56}$ consagra la prohibición de denunciar o de ejercitar la acción penal para los convivientes entre sí y para los condenados por falso testimonio, calumnia o soborno, salvo que lo hagan por delitos cometidos contra ellos o contra su conviviente, entre otros ${ }^{57}$. Además, se le reconoce al conviviente la

48 Código Penal Boliviano [CPB]. Ley 1.768 de 1997. 10 de marzo de 1997 (Bolivia). Art. 91, 3. Disponible en: http://iccdb.webfactional.com/documents/implementations/pdf/Bolivia-Codigo_ Penale_y_Procedimento_Penal.pdf, http://www.wipo.int/wipolex/es/text.jsp?file_id=125360

49 Código Penal Boliviano [CPB]. Ley 1.768 de 1997. 10 de marzo de 1997 (Bolivia). Art. 29. Disponible en: http://iccdb.webfactional.com/documents/implementations/pdf/Bolivia-Codigo_Penale_y_Procedimento_Penal.pdf, http://www.wipo.int/wipolex/es/text.jsp?file_id=125360

50 Código Penal Boliviano [CPB], Ley 1768 de 1997, 10 de marzo de 1997, Art. 75.3. Disponible en: http://iccdb.webfactional.com/documents/implementations/pdf/Bolivia-Codigo_Penale_y_Procedimento Penal.pdf, http://www.wipo.int/wipolex/es/text.jsp?file id=125360

51 Código Penal Boliviano [CPB], Ley 1768 de 1997, 10 de marzo de 1997, Art. 78. Disponible en: http://iccdb.webfactional.com/documents/implementations/pdf/Bolivia-Codigo_Penale_y_Procedimento_Penal.pdf, http://www.wipo.int/wipolex/es/text.jsp?file_id=125360

52 Código Penal Boliviano [CPB], Ley 1768 de 1997, 10 de marzo de 1997, Art. 80. Disponible en: http://iccdb.webfactional.com/documents/implementations/pdf/Bolivia-Codigo_Penale_y_Procedimento_Penal.pdf, http://www.wipo.int/wipolex/es/text.jsp?file_id=125360

53 Código Penal Boliviano [CPB], Ley 1768 de 1997, 10 de marzo de 1997, Art. 252, 1. Disponible en: http://iccdb.webfactional.com/documents/implementations/pdf/Bolivia-Codigo_Penale_y_Procedimento_Penal.pdf, http://www.wipo.int/wipolex/es/text.jsp?file_id=125360

54 Código Penal Boliviano [CPB], Ley 1768 de 1997, 10 de marzo de 1997, Art. 254 inc. 2. Disponible en: http://iccdb.webfactional.com/documents/implementations/pdf/Bolivia-Codigo_Penale_y_Procedimento_Penal.pdf, http://www.wipo.int/wipolex/es/text.jsp?file_id=125360

55 Código Penal Boliviano [CPB], Ley 1768 de 1997, 10 de marzo de 1997, Art. 359, 1. Disponible en: http://iccdb.webfactional.com/documents/implementations/pdf/Bolivia-Codigo_Penale_y_Procedimento_Penal.pdf, http://www.wipo.int/wipolex/es/text.jsp?file_id=125360

56 Código de Procedimiento Penal de Bolivia [CPPB], Ley 1970 de 1999, 25 de marzo de 1999. Disponible en: http://www.wipo.int/wipolex/es/text.jsp?file_id=198177

57 Código de Procedimiento Penal de Bolivia [CPPB]. Ley 1.970 de 1999. 25 de marzo de 1999 (Bolivia). Art. 35. Disponible en: http://www.wipo.int/wipolex/es/text.jsp?file_id=198177 
calidad de víctima en los delitos cuyo resultado sea la muerte del ofendido ${ }^{58}$, al igual que otorga la facultad de abstención, esto es, la de no testificar contra el imputado cuando se trate del conviviente, derecho que deberá serle informado antes de declarar ${ }^{59}$. La denuncia dejará de ser obligatoria cuando pueda dar lugar a la persecución penal propia o del conviviente, entre otras personas y circunstan$\operatorname{cias}^{60}$. De la misma forma les reconoce a los jueces, como causal de excusa y recusación, el ser convivientes de algún interesado o de las partes o el haber recibido beneficios, para sí o para su pareja extramatrimonial ${ }^{61}$. El recurso de revisión puede interponerlo, en cualquier tiempo y a favor del condenado fallecido, el conviviente ${ }^{62}$.

\section{Brasil}

En el Código Penal de Brasil ${ }^{63}$, incluidas las reformas realizadas hasta la ley 11106 de 2005, no se encuentra ninguna referencia a la unión de hecho en los delitos contra la familia ni en los delitos contra la asistencia familiar. El vínculo de compañera o compañero permanente solo es considerado como circunstancia de agravación punitiva para algunos comportamientos punibles, según se reseña en el acápite siguiente.

Por medio de la ley 10886 de 2004 se incluyó en el estatuto punitivo brasileño la violencia doméstica como circunstancia de agravación en el concreto caso de la lesión corporal ${ }^{64}$ realizada contra el compañero (pareja doméstica) o contra quien conviva o hubiera convivido con el agresor, en los casos de lesiones corporales gra-

58 Código de Procedimiento Penal de Bolivia [CPPB], Ley 1970 de 1999, 25 de marzo de 1999, Art. 76.2. Disponible en: http://www.wipo.int/wipolex/es/text.jsp?file_id=198177

59 Código de Procedimiento Penal de Bolivia [CPPB], Ley 1970 de 1999, 25 de marzo de 1999, Art. 196. Disponible en: http://www.wipo.int/wipolex/es/text.jsp?file_id=198177

60 Código de Procedimiento Penal de Bolivia [CPPB], Ley 1970 de 1999, 25 de marzo de 1999, Art. 286 inc. 2. Disponible en: http://www.wipo.int/wipolex/es/text.jsp?file_id=198177

61 Código de Procedimiento Penal de Bolivia [CPPB], Ley 1970 de 1999, 25 de marzo de 1999, Art. 316, 3 y 10. Disponible en: http://www.wipo.int/wipolex/es/text.jsp?file_id=198177

62 Código de Procedimiento Penal de Bolivia [CPPB], Ley 1970 de 1999, 25 de marzo de 1999, Art. 422. Disponible en: http://www.wipo.int/wipolex/es/text.jsp?file_id=198177

63 Código Penal do Brasil [CPBr], Decreto-Lei 2848 de 1940, 7 de diciembre de 1940. Disponible en: http://www.planalto.gov.br/ccivil_03/decreto-lei/del2848.htm

64 Código Penal do Brasil [CPBr], Decreto-Lei 2848 de 1940, 7 de diciembre de 1940, Art. 129, 9. Disponible en: http://www.planalto.gov.br/ccivil_03/decreto-lei/del2848.htm 
$v^{2} s^{65}$, en la lesión seguida de muerte ${ }^{66}$ y en el homicidio culposo $^{67}$; de igual manera, el vínculo de compañero es agravante para el delito de secuestro y detención ilegal ${ }^{68}$; en el de mediación para atender los deseos de otros, favorecimiento de la prostitución, rufianismo, tráfico internacional de personas y tráfico interno de personas ${ }^{69}$, al igual que para el lenocinio, tráfico de personas y, en general, para los delitos contra las costumbres y contra la libertad sexual ${ }^{70}$.

En el Código Penal de Brasil no fue posible encontrar ninguna norma que les brindara una particular protección a las uniones de hecho. Esto solo podría deducirse a partir de los fines que le son reconocidos a la pena en cuanto pretenden realizar prevención general, esto es, en la sociedad; y en especial, respecto del sujeto pasivo para evitar que se vuelva a incurrir en comportamientos que, en el ámbito de esta investigación, atentan contra la unión de hecho como forma de familia o contra alguno de sus integrantes.

\section{E. Chile}

La norma penal chilena ${ }^{71}$ introduce una definición muy particular del elemento normativo "familia", en relación con el suministro de alimentos por el ofensor a los allegados de la víctima en los delitos de homicidio y lesiones, al indicar que "Para los efectos del artículo anterior se entiende por familia todas las personas que tienen derecho a pedir alimentos al ofendido"72. Y, por su parte, el Código Civil no menciona entre los beneficiarios de tales alimentos a los

65 Código Penal do Brasil [CPBr], Decreto-Lei 2848 de 1940, 7 de diciembre de 1940, Art. 129, 1. Disponible en: http://www.planalto.gov.br/ccivil_03/decreto-lei/del2848.htm

66 Código Penal do Brasil [CPBr], Decreto-Lei 2848 de 1940, 7 de diciembre de 1940, Art. 129, 2. Disponible en: http://www.planalto.gov.br/ccivil_03/decreto-lei/del2848.htm

67 Código Penal do Brasil [CPBr], Decreto-Lei $284 \overline{4} 8$ de 1940, 7 de diciembre de 1940, Art. 129, 3. Disponible en: http://www.planalto.gov.br/ccivil_03/decreto-lei/del2848.htm

68 Código Penal do Brasil [CPBr], Decreto-Lei 2848 de 1940, 7 de diciembre de 1940, Art. 148. Disponible en: http://www.planalto.gov.br/ccivil_03/decreto-lei/del2848.htm

69 Código Penal do Brasil [CPBr], Decreto-Lei 2848 de 1940, 7 de diciembre de 1940, Art. 227,1 a 231A. Disponible en: http://www.planalto.gov.br/ccivil_03/decreto-lei/del2848.htm

70 Código Penal do Brasil [CPBr], Decreto-Lei 2848 de 19̄40, 7 de diciembre de 1940, Art. 216. Disponible en: http://www.planalto.gov.br/ccivil_03/decreto-lei/del2848.htm

71 Código Penal Chileno [CPCh], 12 de noviembre de 1874, modificación más reciente: 2 de febrero de 2013. Disponible en: https://www.icrc.org/applic/ihl/ihl-nat.nsf/0/d1f93489752242f8c1256b420 03408c3/\$FILE/COD-Penal_12-NOV-1874.pdf

72 Código Penal Chileno [CPCh], 12 de noviembre de 1874, modificación más reciente: 2 de febrero de 2013, Art. 410 y 411. Disponible en: https://www.icrc.org/applic/ihl/ihl-nat.nsf/0/d1f934897522 42f8c1256b42003408c3/\$FILE/COD-Penal_12-NOV-1874.pdf 
convivientes $^{73}$, de lo cual podría deducirse que estos últimos no podrán solicitar esta clase de perjuicios cuando la víctima sea su compañero o compañera permanente, lo que requerirá un mayor análisis a partir de los conceptos incluidos en la Ley de Violencia Intrafamiliar, para que se pueda avizorar la protección para el compañero.

En la Ley de Violencia Intrafamiliar ${ }^{74}$, el legislador chileno incluyó como punible todo maltrato que afecte la vida o la integridad física o psíquica de quien tenga o haya tenido una relación de convivencia con el ofensor" ${ }^{75}$. Admitió al "conviviente" como miembro de la familia y, en tal condición, como sujeto de especial protección por el Estado.

El maltrato constitutivo de violencia intrafamiliar es castigado con pena de multa, y su valor destinado a la atención de las víctimas de este tipo de violencia en la región respectiva. Además, el juez estará en la obligación de imponer medidas accesorias, como la obligación para el ofensor de abandonar el hogar que comparte con la víctima, la prohibición de acercarse a ella, del porte o tenencia de armas, y la asistencia obligatoria a programas terapéuticos o de orientación familiar. También la obligación de fijarle el aporte de alimentos definitivos, de regular el régimen de cuidado personal, de relación con los hijos, y de resolver las demás cuestiones adicionales $^{76}$. Llama la atención la creación de un Registro de sanciones y medidas accesorias, que deberá ser llevado por el Servicio de Registro Civil e Identificación.

La misma ley sanciona de manera especial el Delito de maltrato habitual, investigable a partir de los antecedentes que el juez de familia le remita al Ministerio Público ${ }^{77}$. De igual manera, se consagra como circunstancia atenuante de la responsabilidad penal la realización de la conducta "en vindicación próxima" de una ofensa

73 Código Civil Chileno [CCCh], 14 de diciembre de 1855, Art. 321. Disponible en: http://www.oas. org/dil/esp/codigo_civil_chile.pdf

74 Chile, Ley 20066 de 2005, por la cual se establece la ley de violencia intrafamiliar, 7 de octubre de 2005. Disponible en: http://www.oas.org/dil/esp/Ley_20066_Violencia_Intrafamiliar_Chile.pdf

75 Chile, Ley 20066 de 2005, por la cual se establece la ley de violencia intrafamiliar, 7 de octubre de 2005, Art. 5. Disponible en: http://www.oas.org/dil/esp/Ley_20066_Violencia_Intrafamiliar_Chile.pdf

76 Chile, Ley 20066 de 2005, por la cual se establece la ley de violencia intrafamiliar, 7 de octubre de 2005, Art. 9. Disponible en: http://www.oas.org/dil/esp/Ley_20066_Violencia_Intrafamiliar_Chile.pdf

77 Chile, Ley 20066 de 2005, por la cual se establece la ley de violencia intrafamiliar, 7 de octubre de 2005, Art. 14. Disponible en: http://www.oas.org/dil/esp/Ley_20066_Violencia_Intrafamiliar_Chile.pdf 
grave causada al autor o a su conviviente, entre otros ${ }^{78} ; y$ también se incluye esta calidad como circunstancia de agravación para algunas acciones relacionadas con los abusos contra particulares por parte de los empleados públicos ${ }^{79}$. En cuanto al delito de homicidio, la conducta se agrava y se castiga como "parricidio" cuando se comete contra quien es o ha sido su conviviente y si la víctima es o ha sido la cónyuge o la conviviente de su autor, el delito tendrá el nombre de "femicidio" $"$. Esta circunstancia de agravación también aplica para el delito de lesiones personales, al quedar comprendidos los convivientes entre las personas mencionadas en el artículo 5 de la Ley de Violencia Intrafamiliar, indicadas en esta agravante ${ }^{81}$.

En el Título de los "Crímenes y delitos contra el orden de las familias, contra la moralidad pública y contra la integridad sexual" del Código Penal, se incluye una regla especial para el caso del conviviente que atenta contra aquel con quien hace vida en común, consistente en poner término al proceso, a petición del ofendido, cualquiera que sea la circunstancia bajo la que se perpetró el delito, salvo que el juez no lo acepte por motivos fundados ${ }^{82}$.

De otra parte, el interés del legislador por proteger a la familia y a sus integrantes, conocible por medio de la Ley de Violencia Intrafamiliar, ha implicado la autorización para la adopción de medidas preventivas o cautelares a favor del conviviente, como todas las correspondientes a las situaciones de riesgo inminente ${ }^{83} \mathrm{y}$ la inclusión, en el numeral 5 del artículo 494 del Código Penal, de la siguiente oración: "En ningún caso el tribunal podrá calificar como leves las lesiones cometidas en contra de las personas mencionadas

78 Código Penal Chileno [CPCh], 12 de noviembre de 1874, modificación más reciente: 2 de febrero de 2013, Art. 11, causal 4. Disponible en: https://www.icrc.org/applic/ihl/ihl-nat.nsf/0/d1f9348975 2242f8c1256b42003408c3/\$FILE/COD-Penal_12-NOV-1874.pdf

79 Código Penal Chileno [CPCh], 12 de noviembre de 1874, modificación más reciente: 2 de febrero de 2013, Art. 259. Disponible en: https://www.icrc.org/applic/ihl/ihl-nat.nsf/0/d1f93489752242f8c 1256b42003408c3/\$FILE/COD-Penal_12-NOV-1874.pdf

80 Código Penal Chileno [CPCh], 12 de noviembre de 1874, modificación más reciente: 2 de febrero de 2013, Art. 390. Disponible en: https://www.icrc.org/applic/ihl/ihl-nat.nsf/0/d1f93489752242f8c 1256b42003408c3/\$FILE/COD-Penal_12-NOV-1874.pdf

81 Código Penal Chileno [CPCh], 12 de noviembre de 1874, modificación más reciente: 2 de febrero de 2013, Art. 400. Disponible en: https://www.icrc.org/applic/ihl/ihl-nat.nsf/0/d1f93489752242f8c 1256b42003408c3/\$FILE/COD-Penal_12-NOV-1874.pdf

82 Código Penal Chileno [CPCh], 12 de noviembre de 1874, modificación más reciente: 2 de febrero de 2013, Art. 369. Disponible en: https://www.icrc.org/applic/ihl/ihl-nat.nsf/0/d1f93489752242f8c 1256b42003408c3/\$FILE/COD-Penal_12-NOV-1874.pdf

83 Chile, Ley 20066 de 2005, por la cual se establece la ley de violencia intrafamiliar, 7 de octubre de 2005, Art. 7. Disponible en: http://www.oas.org/dil/esp/Ley_20066_Violencia_Intrafamiliar_Chile.pdf 
en el artículo 5 de la Ley sobre Violencia Intrafamiliar" ${ }^{84}$, grupo que incluye, como ya se determinó anteriormente, a los convivientes del agresor $u$ ofensor.

\section{F. Ecuador}

Para los primeros días del mes de febrero de 2014 aún se debatía en todos los ámbitos de Ecuador, el Código Orgánico Integral Penal $(\mathrm{COIP})^{85}$, recién aprobado por la Asamblea Nacional con la pretensión de integrar toda la normativa penal existente, que regía desde 1938 y que en más de cuarenta oportunidades, desde 1971 hasta 2010, modificó el Código Penal. En ese nuevo estatuto se incluye en la noción de "miembros del núcleo familiar" a la pareja en unión de hecho o unión libre y a los convivientes, y extiende su protección a aquellos con quienes se mantenga o se haya mantenido una relación consensual de pareja, con expresa referencia a aquellas "personas con las que se determine que el procesado o la procesada mantenga o haya mantenido vínculos familiares, íntimos, afectivos, conyugales, de convivencia, noviazgo o de cohabitación" "86, para el preciso caso de la violencia contra la mujer o miembros del núcleo familiar. También se reafirma la idea de agravar el comportamiento punible cuando la víctima sea el compañero del ofensor, como ocurre con el asesinato, el femicidio y, explotación sexual de personas ${ }^{87}$, prostitución forzada ${ }^{88}$ y en los delitos contra la integridad sexual y reproductiva.

En materia de participación penal, excluye la responsabilidad cuando el encubrimiento se realiza en beneficio del conviviente - lo que también se prevé para el asesinato - sin que puedan ser sancionadas conductas como la violación de la intimidad.

Finalmente, adopta la responsabilidad civil en los hurtos, robos con fuerza en las cosas, defraudaciones o daños que recíprocamente

84 Chile, Ley 20066 de 2005, por la cual se establece la ley de violencia intrafamiliar, 7 de octubre de 2005, Art. 21, literal d. Disponible en: http://www.oas.org/dil/esp/Ley_20066_Violencia_Intrafamiliar_Chile.pdf

85 Código Orgánico Integral Penal Ecuatoriano [COIPE], 28 de enero de 2014. Disponible en: http:// www.ant.gob.ec/index.php/descargable/file/2424-codigo-organico-integral-penal

86 Código Orgánico Integral Penal Ecuatoriano [COIPE], 28 de enero de 2014, Arts. 155, 157 y 159. Disponible en: http://www.ant.gob.ec/index.php/descargable/file/2424-codigo-organico-integral-penal

87 Código Orgánico Integral Penal Ecuatoriano [COIPE], 28 de enero de 2014, Art. 100. Disponible en: http://www.ant.gob.ec/index.php/descargable/file/2424-codigo-organico-integral-penal

88 Código Orgánico Integral Penal Ecuatoriano [COIPE], 28 de enero de 2014, Art. 101. Disponible en: http://www.ant.gob.ec/index.php/descargable/file/2424-codigo-organico-integral-penal 
se causen los convivientes, con la intención de ampliar el radio de influencia y eficacia de la ley penal a estas nuevas situaciones de pareja.

En el aparte correspondiente al Procedimiento Penal, integrado al Libro II del Código, se admite la posibilidad de adquirir la calidad de víctima al "conviviente en unión libre", a los exconvivientes y a las personas con quienes se mantenga o se haya mantenido "una relación consensual de pareja" y, del mismo modo, como causal de excusa o recusación de juezas y jueces, el ser "conviviente en unión de hecho" de alguna de las partes, de su representante legal, de su mandatario, de su abogada o de su abogado defensor; indicando, además, que tampoco serán obligados a testificar esos mismos convivientes, salvo que se trate de casos de violencia intrafamiliar, sexual y de género.

\section{G. Panamá}

La legislación penal vigente de Panamá ${ }^{89}$ utiliza indistintamente o de manera conjunta las expresiones "compañero" o "conviviente" para referirse a los integrantes de la "unión de hecho", al igual que emplea esta última expresión y la de "relación de pareja".

En el caso de la violencia doméstica, incluida como un tipo subsidiario aplicable en aquellos eventos en los que la conducta no constituya delito sancionado con pena mayor, se autoriza este tipo para aquellos casos en los que la agresión sucede en una "unión de hecho" o en una "relación de pareja que no haya cumplido los cinco años, cuya intención de permanencia pueda acreditarse" 90 , disposición que, en concordancia con los cánones constitucionales, asimila estas relaciones afectivas al concepto de familia.

En el Código Penal se otorga la condición de "pariente cercano" al compañero o compañera conviviente del ofensor, calidad que consagra como circunstancia de agravación o atenuación, según la naturaleza, los motivos y los efectos del delito, cuando el agraviado

89 Código Penal Panameño [CPPa], Ley 14 de 2007, 22 de mayo de 2007, con las modificaciones y adiciones introducidas por la Ley 26 de 2008, la Ley 5 de 2009, la Ley 68 de 2009 y la Ley 14 de 2010. Disponible en: https://www.oas.org/juridico/mla/sp/pan/sp_pan-int-text-cp.pdf

90 Código Penal Panameño [CPPa], Ley 14 de 2007, 22 de mayo de 2007, con las modificaciones y adiciones introducidas por la Ley 26 de 2008, la Ley 5 de 2009, la Ley 68 de 2009 y la Ley 14 de 2010, Art. 200. Disponible en: https://www.oas.org/juridico/mla/sp/pan/sp_pan-int-text-cp.pdf 
la ostenta ${ }^{91}$. En concordancia con esta norma rectora, en el delito de aborto provocado se incrementan las penas cuando el culpable de su provocación es el compañero o conviviente ${ }^{92}$, pudiendo deducirse lo mismo para la violación y otros delitos sexuales, en los que se contempla como agravante su perpetración por un pariente cercano ${ }^{93}$.

Pero en los "Delitos contra la Libertad e Integridad Sexual" también se prevé la no aplicación de sanciones en el acceso sexual con persona mayor de 14 años y menor de 18, valiéndose de una condición de ventaja y, aunque medie consentimiento, cuando "entre la víctima y el agente exista una relación de pareja permanente debidamente comprobada y siempre que la diferencia de edad no supere los cinco años"94, lo cual es muy extraño y apresurado porque, al parecer, deja en la impunidad las formas agravadas de los cuatro numerales que en el mismo artículo preceden a esta disposición, lo cual resulta inconcebible cuando se trata de eventos como el contagio de alguna enfermedad de transmisión sexual, además de que no permite suponer el porqué del límite de diferencia de edad señalado.

En los Delitos contra la Familia, incluidos en el Capítulo IV del Título V del Código Penal, no figura ningún punible que revele la intención del legislador por amparar la unión de hecho como una forma de familia, al reprimir aquellas conductas que pudieran llegar a afectarla o a victimizar a uno de sus miembros, aunque podría llegarse a la conclusión contraria, en el evento de la inasistencia alimentaria $^{95}$, de existir alguna disposición legal que impusiera la obligación de prestar alimentos a los compañeros o convivientes.

91 Código Penal Panameño [CPPa], Ley 14 de 2007, 22 de mayo de 2007, con las modificaciones y adiciones introducidas por la Ley 26 de 2008, la Ley 5 de 2009, la Ley 68 de 2009 y la Ley 14 de 2010, Art. 91. Disponible en: https://www.oas.org/juridico/mla/sp/pan/sp_pan-int-text-cp.pdf

92 Código Penal Panameño [CPPa], Ley 14 de 2007, 22 de mayo de 2007, con las modificaciones y adiciones introducidas por la Ley 26 de 2008, la Ley 5 de 2009, la Ley 68 de 2009 y la Ley 14 de 2010, Art. 143. Disponible en: https://www.oas.org/juridico/mla/sp/pan/sp_pan-int-text-cp.pdf

93 Código Penal Panameño [CPPa], Ley 14 de 2007, 22 de mayo de 2007, con las modificaciones y adiciones introducidas por la Ley 26 de 2008, la Ley 5 de 2009, la Ley 68 de 2009 y la Ley 14 de 2010, Art. 174, 4 y 177, 2. Disponible en: https://www.oas.org/juridico/mla/sp/pan/sp_pan-int-textcp.pdf

94 Código Penal Panameño [CPPa], Ley 14 de 2007, 22 de mayo de 2007, con las modificaciones y adiciones introducidas por la Ley 26 de 2008, la Ley 5 de 2009, la Ley 68 de 2009 y la Ley 14 de 2010, Art. 176. Disponible en: https://www.oas.org/juridico/mla/sp/pan/sp_pan-int-text-cp.pdf

95 Código Penal Panameño [CPPa], Ley 14 de 2007, 22 de mayo de 2007, con las modificaciones y adiciones introducidas por la Ley 26 de 2008, la Ley 5 de 2009, la Ley 68 de 2009 y la Ley 14 de 2010, Art. 211. Disponible en: https://www.oas.org/juridico/mla/sp/pan/sp_pan-int-text-cp.pdf 


\section{H. Paraguay}

El Código Penal de Paraguay data de 1997, año en el que fue proferida la Ley 1160 de 26 de noviembre, que lo contiene. Fue modificado parcialmente por medio de las Leyes 1340 de 1998, 3440 de 16 de julio de 2008, 4628 de 2012 y 4770 de 2012. En el numeral 12 del artículo 14, que relaciona las definiciones establecidas para los efectos de la ley penal, se precisa que son parientes "...los consanguíneos hasta el cuarto grado, el cónyuge y los afines en línea recta hasta el segundo grado, sin considerar... a) la filiación matrimonial o extramatrimonial...".

La ley procesa $1^{96}$, por su parte, incluye en el concepto de víctima al conviviente ${ }^{97}$, al tiempo que le reconoce la facultad de abstención para declarar ${ }^{98}$ y lo excusa de la obligación de denunciar ${ }^{99}$, sin dejar de anotar que también lo legitima para promover el recurso de revisión ${ }^{100}$.

La Ley 4628 de 2012 modificó el artículo 229 del actual Código Penal Paraguayo ${ }^{101}$, sobre "violencia familiar", con el que se desarrolla el precepto constitucional del artículo 60, que obliga al Estado a promover políticas que tengan por objeto evitar la violencia en el ámbito familiar y otras causas destructoras de su solidaridad. Con este tipo penal se sanciona la violencia que, en el ámbito familiar, se

96 Código Procesal Penal Paraguayo [CPP], Ley 1286 de 1998, 8 de julio de 1998. Disponible en: http://www.iadb.org/Research/legislacionindigena/leyn/docs/Para-Para-Codigo-Procesal-PenalLey-1286-98-.pdf

97 Código Procesal Penal Paraguayo [CPP], Ley 1286 de 1998, 8 de julio de 1998, Art. 67.2. Disponible en: http://www.iadb.org/Research/legislacionindigena/leyn/docs/Para-Para-Codigo-Procesal-PenalLey-1286-98-.pdf

98 Código Procesal Penal Paraguayo [CPP], Ley 1286 de 1998, 8 de julio de 1998, Art. 205. Disponible en: http://www.iadb.org/Research/legislacionindigena/leyn/docs/Para-Para-Codigo-Procesal-PenalLey-1286-98-.pdf

99 Código Procesal Penal Paraguayo [CPP], Ley 1286 de 1998, 8 de julio de 1998, Arts. 286 y 287. Disponible en: http://www.iadb.org/Research/legislacionindigena/leyn/docs/Para-Para-CodigoProcesal-Penal-Ley-1286-98-.pdf

100 Código Procesal Penal Paraguayo [CPP], Ley 1286 de 1998, 8 de julio de 1998, Art. 482. Disponible en: http://www.iadb.org/Research/legislacionindigena/leyn/docs/Para-Para-Codigo-Procesal-PenalLey-1286-98-.pdf

101 Código Penal Paraguayo [CPPy], Ley 1160 de 1997, 26 de noviembre 26 de 1997, Art. 229, modificado por la Ley 3440 de 2008. Disponible en: http://www.mre.gov.py/v1/Adjuntos/Privacidad/Ley1160. pdf, http://www.redipd.org/legislacion/common/legislacion/paraguay/Ley_3440.pdf Paraguay, Ley 4628, que modifica el artículo 229 de la Ley 1160/97, Código Penal, modificado por la Ley 3440/08, 29 de junio de 2012. Disponible en: http://www.bacn.gov.py/ MjcxMA==\&ley-n-4628 
ejerza en forma reiterada sobre otra persona con quien se conviva, sin limitación exclusiva a la institución matrimonial y sin exigir esa reiteración en los casos con lesiones.

En términos generales, el estatuto punitivo sanciona las conductas que atentan contra la convivencia de las personas y de manera particular los comportamientos punibles vulneradores del estado civil, el matrimonio y la familia ${ }^{102}$, sin limitar ni precisar sus alcances en el ámbito de los sujetos activos o pasivos de tales acciones, como ocurre en delitos como el del incumplimiento del deber legal alimentario $^{103}$.

Hay otros tipos penales, como el de abuso sexual en personas bajo tutela ${ }^{104}$, en los que se sanciona expresamente la realización de actos sexuales o la inducción a los mismos, "con un hijo biológico, adoptivo o hijastro del cónyuge o concubino", aunque sin consagrar expresamente alguna causal de agravación derivada de tal condición.

En el homicidio doloso ${ }^{105}$ se agrava la pena para el autor del delito cuando mata a su cónyuge o concubino, aunque llama la atención que con la modificación de la Ley 3440 se hubiera cambiado esta última expresión por su femenino "concubina".

Como medida preventiva y, al mismo tiempo, como reconocimiento de la importancia del vínculo afectivo que puede surgir o existe entre convivientes, es posible encontrar en la ley procesal penal normas como el artículo 50, en cuyos numerales 1 y 2 se admite como un motivo de excusación o recusación de los jueces la existencia de tal relación con alguna de las partes o con su representante legal

102 Código Penal Paraguayo [CPPy], Ley 1160 de 1997, 26 de noviembre 26 de 1997, Título IV, Capítulo I, modificado por la Ley 3440 de 2008. Disponible en: http://www.mre.gov.py/v1/ Adjuntos/Privacidad/Ley1160.pdf, http://www.redipd.org/legislacion/common/legislacion/ paraguay/Ley_3440.pdf

103 Código Penal Paraguayo [CPPy], Ley 1160 de 1997, 26 de noviembre 26 de 1997, Art. 225, modificado por la Ley 3440 de 2008. Disponible en: http:/www.mre.gov.py/v1/Adjuntos/ Privacidad/Ley1160.pdf, http://www.redipd.org/legislacion/common/legislacion/paraguay/ Ley_3440.pdf

104 Código Penal Paraguayo [CPPy], Ley 1160 de 1997, 26 de noviembre 26 de 1997, Art. 136.3, modificado por la Ley 3440 de 2008. Disponible en: http://www.mre.gov.py/v1/Adjuntos/ Privacidad/Ley1160.pdf, http://www.redipd.org/legislacion/common/legislacion/paraguay/ Ley_3440.pdf

105 Código Penal Paraguayo [CPPy], Ley 1160 de 1997, 26 de noviembre 26 de 1997, Art. 105, modificado por la Ley 3440 de 2008. Disponible en: http://www.mre.gov.py/v1/Adjuntos/ Privacidad/Ley1160.pdf, http://www.redipd.org/legislacion/common/legislacion/paraguay/ Ley_3440.pdf 
o convencional o, incluso, cuando ese vínculo resulta predicable respecto del conviviente del funcionario y con relación a alguna de las partes ${ }^{106}$. Otro tanto ocurre con el representante del Ministerio Público $^{107}$, a la par que le reconoce al imputado el derecho a que su conviviente le designe un defensor ${ }^{108}$. Pero en concreto, no es posible encontrar normas que prevengan cualquier atentado contra el conviviente o compañero, salvo las correspondientes a los tipos penales anteriormente señalados.

\section{Perú}

El Código Penal de la República del Perú, adoptado mediante Decreto Legislativo 635, promulgado el 8 de abril de 1991, tampoco es ajeno a la protección de los convivientes, debiendo aclararse sobre este particular que la expresión inicial de "concubino" fue posteriormente reemplazada por la de "conviviente", seguramente para darle un mayor alcance y para eliminar la connotación despectiva que la primera forma podría contener, aunque sin eliminarla totalmente del código. Se destaca además, que en este estatuto se consagra como una "excusa absolutoria" para exención de pena, los hurtos, apropiaciones, defraudaciones o daños que se causen, entre otros, los concubinos ${ }^{109}$.

En materia procesal, existe la garantía de "abstención para rendir testimonio" que incluye a los cónyuges y convivientes "aun cuando haya cesado el vínculo conyugal o convivencial" del imputado y que los faculta para rehusarse a declarar.

106 Código Penal Paraguayo [CPPy], Ley 1160 de 1997, 26 de noviembre 26 de 1997, Art. 50.3, modificado por la Ley 3440 de 2008. Disponible en: http://www.mre.gov.py/v1/Adjuntos/ Privacidad/Ley1160.pdf, http://www.redipd.org/legislacion/common/legislacion/paraguay/ Ley_3440.pdf

107 Código Penal Paraguayo [CPPy], Ley 1160 de 1997, 26 de noviembre 26 de 1997, Art. 57, modificado por la Ley 3440 de 2008. Disponible en: http://www.mre.gov.py/vl/Adjuntos/Privacidad/ Ley1160.pdf, http://www.redipd.org/legislacion/common/legislacion/paraguay/Ley_3440.pdf

108 Código Penal Paraguayo [CPPy], Ley 1160 de 1997, 26 de noviembre 26 de 1997, Art. 74.4, modificado por la Ley 3440 de 2008. Disponible en: http://www.mre.gov.py/v1/Adjuntos/ Privacidad/Ley1160.pdf, http://www.redipd.org/legislacion/common/legislacion/paraguay/ Ley_3440.pdf

109 Código Penal Peruano [CPPe], Decreto Legislativo 635 de 1991, 8 de abril de 1991, Art. 208 (este artículo hace parte de un capítulo único incorporado por la Ley 27309 de 2000). Disponible en: http://spij.minjus.gob.pe/CLP/contenidos.dll?f=templates\&fn=default-codpenal. htm\&vid=Ciclope:CLPdemo 
En la normatividad penal es manifiesta la protección que se le brinda a la unión de hecho, al otorgarle la misma categoría que al matrimonio al reprimir por igual, en el delito de parricidio $^{110}$, al que a sabiendas mata "a quien es o ha sido su cónyuge, su conviviente, $o$ con quien esté sosteniendo o haya sostenido una relación análoga", precisando, además, que este delito tomará la denominación de "feminicidio" cuando la víctima de tal acción y en tales condiciones sea una mujer.

La protección penal a la unión de hecho también se materializa por la agravación de los comportamientos realizados mediante el aprovechamiento de tal vínculo con la víctima o no obstante su existencia, lo cual puede observarse en delitos como el de lesiones ${ }^{111}$ y en la forma agravada de los delitos de trata de personas ${ }^{112}$, violación sexual $^{113}$ y tráfico ilícito de migrantes, y rufianismo ${ }^{114}$, con expresa mención al conviviente y a sus hijos.

Se mantuvo la denominación de "concubino" para agravar varias conductas, según se anunció anteriormente, como el favorecimiento a la prostitución ${ }^{115}$, el proxenetismo (incluyendo a los hijos de la persona concubina) $)^{116}$ y el maltrato $^{117}$.

110 Código Penal Peruano [CPPe], Decreto Legislativo 635 de 1991, 8 de abril de 1991, Art. 106, modificado por el Artículo Único de la Ley 29819 de 27 de diciembre de 2011. Disponible en: http://spij.minjus.gob.pe/CLP/contenidos.dll?f=templates\&fn=default-codpenal. htm\&vid=Ciclope:CLPdemo

111 Código Penal Peruano [CPPe], Decreto Legislativo 635 de 1991, 8 de abril de 1991, Art. 121 A y 122 A, antes de las modificaciones introducidas por las Leyes 26788 de 16/05/1997, 29282 de 27/11/2008 y 29699 de 04/06/2011. Disponible en: http://spij.minjus.gob.pe/CLP/contenidos. $\mathrm{dll}$ ?f=templates \&fn=default-codpenal.htm\&vid=Ciclope:CLPdemo

112 Código Penal Peruano [CPPe], Decreto Legislativo 635 de 1991, 8 de abril de 1991, Art. 153 A, 5, modificado por la Ley 28950 de 2007. Disponible en: http://spij.minjus.gob.pe/CLP/ contenidos.dll?f=templates\&fn=default-codpenal.htm\&vid=Ciclope:CLPdemo

113 Código Penal Peruano [CPPe], Decreto Legislativo 635 de 1991, 8 de abril de 1991 (Perú), Art. 170, modificado por la Ley 28704 de 2006. Disponible en: http://spij.minjus.gob.pe/CLP/ contenidos.dll?f=templates\&fn=default-codpenal.htm\&vid=Ciclope:CLPdemo

114 Código Penal Peruano [CPPe], Decreto Legislativo 635 de 1991, 8 de abril de 1991, Art. 180, modificado por la Ley 28251 de 2004. Disponible en: http://spij.minjus.gob.pe/CLP/contenidos. $\mathrm{dll}$ ?f=templates \&fn=default-codpenal.htm\&vid=Ciclope:CLPdemo

115 Código Penal Peruano [CPPe], Decreto Legislativo 635 de 1991, 8 de abril de 1991, Art. 179, modificado por la Ley 28251 de 2004. Disponible en: http://spij.minjus.gob.pe/CLP/contenidos. $\mathrm{dll}$ ?f=templates $\& \mathrm{fn}=$ default-codpenal.htm\&vid=Ciclope:CLPdemo

116 Código Penal Peruano [CPPe], Decreto Legislativo 635 de 1991, 8 de abril de 1991, Art. 181, modificado por la Ley 28251 de 2004. Disponible en: http://spij.minjus.gob.pe/CLP/contenidos. dll?f=templates\&fn=default-codpenal.htm\&vid=Ciclope:CLPdemo

117 Código Penal Peruano [CPPe], Decreto Legislativo 635 de 1991, 8 de abril de 1991, Art. 442. Disponible en: http://spij.minjus.gob.pe/CLP/contenidos.dll?f=templates\&fn=default-codpenal. htm\&vid=Ciclope:CLPdemo 
Aunque de las normas anteriormente mencionadas del estatuto punitivo resulta posible inferir la prevención especial y general como objetivos de la pena, la verdadera o más clara prevención se encuentra en la legislación procesal del Perú, que a partir de la indicación de las personas destinatarias de las medidas de protección ${ }^{118}$, entre las que se incluye al conviviente, establece una relación de estas mientras se mantenga la situación de peligro grave, y también las medidas adicionales, su variación y reexamen y los correspondientes programas de protección.

\section{J. URUGUAY}

La Ley 9155 de 4 de diciembre de 1933, contentiva del Código Penal de ese país, si bien ha tenido múltiples modificaciones y adiciones, sigue siendo un estatuto desactualizado. Por ejemplo, en el artículo 36 se incluye como circunstancia que exime de pena y por lo tanto constituye una "causa de impunidad", la "pasión provocada por el adulterio", pues autoriza al juez a exonerar de pena en los delitos de homicidio y lesiones, cuando se reúnan los siguientes requisitos: "1. Que el delito se cometa por el cónyuge que sorprendiera infraganti al otro cónyuge y que se efectúe contra este o contra el amante. 2. Que el autor tuviera buenos antecedentes y que la oportunidad para cometer el delito no hubiera sido provocada o simplemente facilitada mediando conocimiento anterior de la infidelidad conyugal"'119. Esto, además, opera exclusivamente para los matrimonios legalmente formalizados y no para las uniones de hecho.

No fue posible encontrar en el Código Penal, no obstante las reformas realizadas desde 1934 hasta el 3 de octubre de 2013, cuando se le hizo una adición con la Ley 19138 (sin desconocer las muy importantes modificaciones al articulado efectuadas por medio de la Ley 19120 de 20 de agosto de 2013), ni una sola descripción típica que sancionara los comportamientos reprochables que pudieran atentar contra las uniones de hecho.

118 Código Procesal Penal Peruano [CPP], Decreto Legislativo 957 de 2004, 29 de julio de 2004, Art. 247. Disponible en: http://spij.minjus.gob.pe/CLP/contenidos.dll?f=templates\&fn=defaultnuevocodprocpenal.htm\&vid=Ciclope:CLPdemo

119 Código Penal Uruguayo [CPU], Ley 9155 de 1933, 4 de diciembre de 1933. Entró en vigencia con la Ley 9414 de 29/06/1934. Versión oficial publicada mediante Decreto 698 de 26/10/1967, Art. 36. Disponible en: http://www.parlamento.gub.uy/Codigos/CodigoPenal/Cod_Pen.htm 
La familia, de acuerdo con el Código Civil de Uruguay,

...comprende el cónyuge y los hijos legítimos y naturales reconocidos o declarados tales, tanto los que existen al tiempo de constituirse el derecho, como los que sobrevienen después.

Comprende asimismo el número de sirvientes necesarios para la familia.

Comprende, además, las personas que a la misma fecha vivían con el habitador o usuario y a costa de estos; y las personas a quienes estos deben alimentos ${ }^{120}$.

De esta definición no es posible deducir si la expresión "comprende" alcanza a integrar como constitutivos de la familia, en desarrollo de su último inciso, a los compañeros permanentes que vivan con el habitador o usuario y a su costa, sin importar su sexo.

De otra parte, la ley procesal penal ${ }^{121}$ tampoco contiene ninguna norma que permita colegir, fundadamente, que el legislador ha procurado brindarle alguna protección especial a este tipo de uniones de pareja, con la única opción, dependiente de las interpretaciones doctrinarias o jurisprudenciales, de considerarlas incluidas en el concepto de "familia" utilizado en varias de sus normas.

Sí se observa, entre las circunstancias agravantes especiales para el delito de homicidio, el cometerlo en la persona del concubino o concubina "more uxorio"122, pero esta es la única forma de protección de la unión de hecho o de sus integrantes que puede encontrarse en ese estatuto. El artículo 261 contiene algunas formas agravadas para los delitos "Contra las buenas costumbres y el orden de la familia", donde no se hace ninguna mención al concubino, conviviente, compañero permanente, partenario civil o pareja de hecho, por lo que bien pueden ser considerados como excluidos de protección.

En definitiva, la legislación penal de este país, salvo las referencias a las uniones de hecho ya comentadas, no contempla ninguna disposición

120 Código Civil Uruguayo [CCU], Ley 16603 de 1994, 19 de octubre de 1994, Art. 545. Disponible en: http://www.parlamento.gub.uy/htmlstat/pl/codigos/CodigoCivil/2002/cod_civil-indice.htm

121 Código del Proceso Penal Uruguayo [CPP], Ley 15032 de 1980, 7 de julio de 1980. Disponible en: http://www.parlamento.gub.uy/leyes/AccesoTextoLey.asp?Ley=15032\&Anchor=

122 Código Penal Uruguayo [CPU], Ley 9155 de 1933, 4 de diciembre de 1933. Entró en vigencia con la Ley 9414 de 29/06/1934. Versión oficial publicada mediante Decreto 698 de 26/10/1967, Art 311, 1. Disponible en: http://www.parlamento.gub.uy/Codigos/CodigoPenal/Cod_Pen.htm La convivencia more uxorio o unión de hecho es aquella integrada voluntariamente por una pareja con comunidad de vida familiar e intereses, caracterizada por la permanencia estable y pública, consolidada por el transcurso del tiempo y con apariencia de matrimonio. 
o medida que tienda a prevenir los atentados contra la integridad de las uniones de hecho o contra los que han decidido establecer esa relación de convivencia permanente e informal.

\section{K. Venezuela}

El Código Penal de la República Bolivariana de Venezuela ${ }^{123}$ incluye entre sus tipos penales el de adulterio en varias modalidades, en algunas de las cuales figura la concubina como coautora del delito ${ }^{124}$. Es esa la única referencia que se encuentra en toda la normativa con relación a la pareja de hecho, limitándose la protección, en los demás casos, al cónyuge víctima únicamente, como ocurre con el delito de homicidio, para el que se incrementa la pena por la existencia del vínculo matrimonial y se le niega al sujeto activo "la gracia de la conmutación" 125 .

Esto es algo que debe ser cambiado porque se trata de una normativa que no consulta la realidad social del momento, no resulta acorde con lo pregonado en el artículo 77 de la Constitución Política y mucho menos con el reconocimiento jurídico que a las uniones concubinarias se les ha otorgado en ámbitos específicos ${ }^{126}$.

123 Código Penal Venezolano [CPV], 20 de octubre de 2000, 3 de marzo de 2005. Disponible en: http:// www.oas.org/juridico/spanish/mesicic3_ven_anexo6.pdf. Reforma de 2005 disponible en: http:// www.oas.org/juridico/spanish/mesicic3_ven_anexo7.pdf

124 Código Penal Venezolano [CPV], 20 de octubre de 2000, 3 de marzo de 2005, Art. 395 y ss. Disponible en: http://www.oas.org/juridico/spanish/mesicic3_ven_anexo6.pdf. Reforma de 2005 disponible en: http://www.oas.org/juridico/spanish/mesicic3_ven_anexo7.pdf

125 Código Penal Venezolano [CPV], 20 de octubre de 2000, 3 de marzo de 2005, Art. 56. Disponible en: http://www.oas.org/juridico/spanish/mesicic3_ven_anexo6.pdf. Reforma de 2005 disponible en: http://www.oas.org/juridico/spanish/mesicic3_ven_anexo7.pdf

Sobre esta gracia, precisa la ley penal: "Artículo 53. Todo reo condenado a presidio o prisión o destinado a penitenciaría o establecimiento penitenciario, que haya cumplido las tres cuartas partes de su condena, observando conducta ejemplar, puede ocurrir al Tribunal Supremo de Justicia, en escrito autenticado, solicitando la conmutación del resto de la pena en la de relegación a una colonia penitenciaria por el mismo tiempo o confinamiento por un tiempo igual al que resta de la pena, con aumento de una tercera parte".

126 Marisela Párraga de Esparza, Las uniones estables de hecho en la constitución venezolana de 1999, 2 Cuestiones Jurídicas. Revista de Ciencias Jurídicas de la Universidad Rafael Urdaneta, 1, 11-39, 13 (enero-junio de 2008). Disponible en: http://www.redalyc.org/articulo.oa?id=127519339002 


\section{CONCLUSIONES}

- En líneas generales, el reconocimiento y la protección que la ley penal les brinda a las uniones de hecho en Latinoamérica son palmarios. En algunos de estos países, sin embargo, la legislación penal se erige en una cortapisa para ampararlas de manera franca y decidida. Esto, porque sus códigos resultan ajenos a las nuevas realidades sociales y porque, ante la ausencia de reformas estructurales y profundas, aún se conservan instituciones que ya fueron superadas en otros lugares y se reprimen comportamientos que la sociedad ya no reprocha, porque las razones morales y religiosas han cambiado y han evolucionado hacia nuevas formas menos intervencionistas, más tolerantes y más respetuosas de la intimidad de las personas.

- La protección de las uniones de hecho, en el ámbito penal latinoamericano, se realiza en tres formas particulares: i) reprimiendo las conductas que atentan contra su integración o la convivencia de sus miembros mediante la inclusión de nuevos tipos penales en los códigos o estatutos punitivos; ii) consagrando como circunstancias de agravación o de atenuación de los comportamientos punibles, situaciones como la condición de compañero permanente del agresor respecto de su víctima o la de desarrollar la acción en defensa del compañero o conviviente; y iii) tomando en consideración la relación existente con la pareja como presupuesto para conceder o negar un determinado beneficio o subrogado en la sentencia.

- El principal efecto de la protección de las uniones de hecho en la ley penal, además de su tácito reconocimiento como formas naturales de familia, es el de la prevención, especial y general, de futuros delitos contra sus integrantes.

- El reconocimiento de las uniones de hecho - heterosexuales y homosexuales - como formas de familia constituidas por vínculos naturales, conlleva la necesidad de implementar leyes que contribuyan a su amparo en el ámbito del derecho penal, campo en el cual debe unificarse el concepto de familia para incluir en él a los compañeros y a las compañeras permanentes como sujetos de especial protección. Los Estados deben entonces definir políticas públicas claras, concretamente en materia 
criminal, destinadas a convertir en realidad estas pretensiones, bajo la consideración de que no existe una razón atendible que justifique su desconocimiento o discriminación. 


\section{BIBLIOGRAFÍA}

\section{Revistas}

Blanco-Rodríguez, Jinyola \& SANTACruz-López, Raúl, La exclusión legal del abuso sexual entre cónyuges o compañeros permanentes como forma de violencia intrafamiliar, 118 Vniversitas, 141-159 (enero-junio de 2009). Disponible en: http:// www.redalyc.org/articulo.oa?id=82516351006

Grosman, Cecilia \& Guillot, María Alejandra, Derecho del conviviente a la afiliación de su pareja estable a una obra social, Diario La Ley (24 de febrero de 2005). Disponible en: http://www.aabioetica.org/juris/baxo5.htm

Párraga de Esparza, Marisela, Las uniones estables de hecho en la constitución venezolana de 1999, 2 Cuestiones Jurídicas. Revista de Ciencias Jurídicas de la Universidad Rafael Urdaneta, 1, 11-39 (enero-junio de 2008). Disponible en: http:// www.redalyc.org/articulo.oa?id=127519339002

\section{Legislación colombiana}

Código Penal Colombiano [CPC], Ley 599 de 2000, por la cual se expide el Código Penal. 24 de julio de 2000, 44097 Diario Oficial, 24 de julio de 2000. Disponible en: http://www.alcaldiabogota.gov.co/sisjur/normas/Norma1.jsp?i=6388

Código Penitenciario y Carcelario de Colombia [CPyC], Ley 1709 de 20 de 2014, por medio de la cual se reforman algunos artículos de la ley 65 de 1993, de la ley 599 de 2000, de la ley 55 de 1985 y se dictan otras disposiciones. 20 de enero de 2014, 49039 Diario Oficial, 20 de enero de 2014. Disponible en: http://www.icbf.gov. co/cargues/avance/docs/ley_1709_2014.htm

Constitución Política de Colombia [Const], 7 de julio de 1991. Disponible en: http:// www.alcaldiabogota.gov.co/sisjur/normas/Norma1.jsp?i=4125

Ley 54 de 1990, por la cual se definen las uniones maritales de hecho y régimen patrimonial entre compañeros permanentes, 28 de diciembre de 1990, 39615 Diario Oficial, 31 de diciembre de 1990. Disponible en: http://www.alcaldiabogota.gov.co/sisjur/ normas/Norma1.jsp?i=30896

\section{Jurisprudencia colombiana}

Corte Constitucional de Colombia, Sentencia C-029-09, 28 de enero de 2009, magistrado ponente Rodrigo Escobar-Gil. Disponible en: http://www.corteconstitucional. gov.co/relatoria/2009/c-029-09.htm

Corte Constitucional de Colombia, Sentencia C-238-12, 22 de marzo de 2012, magistrado ponente Gabriel Eduardo Mendoza-Martelo. Disponible en: http://www. corteconstitucional.gov.co/relatoria/2012/c-238-12.htm 


\section{Tratados internacionales}

Organización de Estados Americanos, OEA, Convención Americana sobre Derechos Humanos, San José de Costa Rica, 22 de noviembre de 1969. Disponible en: http://www.oas.org/dil/esp/tratados_b-32_convencion_americana_sobre_ derechos_humanos.htm

Organización de Naciones Unidas, ONU, Declaración Universal de Derechos Humanos, adoptada y proclamada por la Asamblea General, Resolución 217 A (III), 10 de diciembre de 1948. Disponible en: http://www.acnur.org/t3/fileadmin/ Documentos/BDL/2001/0013.pdf?view=1

Organización de Naciones Unidas, ONU, Pacto Internacional de Derechos Civiles y Políticos, adoptado y proclamado por la Asamblea General, Resolución 2200 A (XXI), 16 de diciembre de 1966. Disponible en: http://www.ohchr.org/SP/ ProfessionalInterest/Pages/CCPR.aspx

\section{Legislación internacional}

Chile, Ley 20066 de 2005, por la cual se establece la ley de violencia intrafamiliar, 7 de octubre de 2005. Disponible en: http://www.oas.org/dil/esp/Ley_20066_ Violencia_Intrafamiliar_Chile.pdf

Código Civil Chileno [CCCh], 14 de diciembre de 1855. Disponible en: http://www.oas. org/dil/esp/codigo_civil_chile.pdf

Código Civil Uruguayo [CCU], Ley 16603 de 1994, 19 de octubre de 1994. Disponible en: http://www.parlamento.gub.uy/htmlstat/pl/codigos/CodigoCivil/2002/ cod_civil-indice.htm

Código de Procedimiento Penal de Bolivia [CPPB], Ley 1970 de 1999, 25 de marzo de 1999. Disponible en: http://www.wipo.int/wipolex/es/text.jsp?file_id=198177

Código del Proceso Penal Uruguayo [CPP], Ley 15032 de 1980, 7 de julio de 1980. Disponible en: http://www.parlamento.gub.uy/leyes/AccesoTextoLey. asp?Ley $=15032 \&$ Anchor $=$

Código Orgánico Integral Penal Ecuatoriano [COIPE], 28 de enero de 2014. Disponible en: http://www.ant.gob.ec/index.php/descargable/file/2424-codigo-organicointegral-penal

Código Penal Boliviano [CPB], Ley 1768 de 1997, 10 de marzo de 1997. Disponible en: http://iccdb.webfactional.com/documents/implementations/pdf/BoliviaCodigo_Penale_y_Procedimento_Penal.pdf, http://www.wipo.int/wipolex/es/ text.jsp?file_id=125360

Código Penal Chileno [CPCh], 12 de noviembre de 1874. Modificación más reciente: 2 de febrero de 2013. Disponible en: https://www.icrc.org/applic/ihl/ihl-nat.nsf/0/ d1f93489752242f8c1256b42003408c3/\$FILE/COD-Penal_12-NOV-1874.pdf

Código Penal de la Nación Argentina [CPA], Ley 11179 de 1921, 3 de noviembre de 1921. Disponible en: http://www.infoleg.gov.ar/infolegInternet/ anexos/15000-19999/16546/texact.htm 
Código Penal do Brasil [CPBr], Decreto-Lei 2848 de 1940, 7 de diciembre de 1940. Disponible en: http://www.planalto.gov.br/ccivil_03/decreto-lei/del2848.htm

Código Penal Panameño [CPPa], Ley 14 de 2007, 22 de mayo de 2007, con las modificaciones y adiciones introducidas por la Ley 26 de 2008, la Ley 5 de 2009, la Ley 68 de 2009 y la Ley 14 de 2010. Disponible en: https://www.oas.org/juridico/ $\mathrm{mla} / \mathrm{sp} / \mathrm{pan} / \mathrm{sp} \_$pan-int-text-cp.pdf

Código Penal Paraguayo [CPPy], Ley 1160 de 1997, 26 de noviembre 26 de 1997, modificado por la Ley 3440 de 2008. Disponible en: http://www.mre.gov.py/vl/ Adjuntos/Privacidad/Ley1160.pdf, http://www.redipd.org/legislacion/common/ legislacion/paraguay/Ley_3440.pdf

Código Penal Peruano [CPPe], Decreto Legislativo 635 de 1991, 8 de abril de 1991. Disponible en: http://spij.minjus.gob.pe/CLP/contenidos.dll?f=templates\&fn=defaultcodpenal.htm\&vid=Ciclope:CLPdemo

Código Penal Uruguayo [CPU], Ley 9155 de 1933, 4 de diciembre de 1933. Entró en vigencia con la Ley 9414 de 29/06/1934. Versión oficial publicada mediante Decreto 698 de 26/10/1967. Disponible en: http://www.parlamento.gub.uy/ Codigos/CodigoPenal/Cod_Pen.htm

Código Penal Venezolano [CPV], 20 de octubre de 2000, 3 de marzo de 2005. Disponible en: http://www.oas.org/juridico/spanish/mesicic3_ven_anexo6.pdf. Reforma de 2005 disponible en: http://www.oas.org/juridico/spanish/mesicic3_ven_anexo7. pdf

Código Procesal Penal Argentino [CPP], Ley 23984 de 1991, 4 de septiembre de 1991. Disponible en: http://www.infoleg.gov.ar/infolegInternet/anexos/0-4999/383/ texact.htm

Código Procesal Penal Paraguayo [CPP], Ley 1286 de 1998, 8 de julio de 1998. Disponible en: http://www.iadb.org/Research/legislacionindigena/leyn/docs/Para-ParaCodigo-Procesal-Penal-Ley-1286-98-.pdf

Código Procesal Penal Peruano [CPP], Decreto Legislativo 957 de 2004, 29 de julio de 2004. Disponible en: http://spij.minjus.gob.pe/CLP/contenidos. $\mathrm{dll}$ ?f=templates\&fn=default-nuevocodprocpenal.htm\&vid=Ciclope:CLPdemo

Constitución de la Nación Argentina [Const], 22 de agosto de 1994. Disponible en: http:// infoleg.mecon.gov.ar/infolegInternet/anexos/0-4999/804/norma.htm, http://www. constitution.org/cons/argentin.htm

Constitución de la República Bolivariana de Venezuela [Const], 20 de diciembre de 1999. Disponible en: http://www.cne.gov.ve/web/normativa_electoral/constitucion/ indice.php

Constitución de la República de Paraguay [Const], 20 de junio de 1992. Disponible en: http://www.bacn.gov.py/constitucion-nacional-de-la-republica-del-paraguay.php

Constitución de la República del Ecuador [Const], 20 de octubre de 2008. Disponible en: http://pdba.georgetown.edu/Parties/Ecuador/Leyes/constitucion.pdf

Constitución de la República Federativa de Brasil [Const], 5 de octubre de 1988. Disponible en: http://pdba.georgetown.edu/Constitutions/Brazil/esp88. html\#mozTocId757336, texto en portugués http://www.wipo.int/edocs/lexdocs/ 
laws/pt/br/br159pt.pdf, http://www.planalto.gov.br/ccivil_03/constituicao/ constituicao.htm

Constitución Política de la República de Chile [Const], 11 de septiembre de 1980. Disponible en: http://www.senado.cl/constitucion-politica-capitulo-i-bases-dela-institucionalidad/prontus_senado/2012-01-16/093048.html

Constitución Política de la República de Panamá [Const], 15 de noviembre de 2004. Disponible en: http://www.organojudicial.gob.pa/cendoj/cendojfields/ constitucion-politica/

Constitución Política de la República Oriental del Uruguay [Const], 14 de enero de 1997. Disponible en: http://www.parlamento.gub.uy/constituciones/const004.htm

Constitución Política del Estado Plurinacional de Bolivia [Const], 7 de febrero de 2009. Disponible en: http://www.ncpe.org.bo/

Constitución Política del Perú [Const], 29 de diciembre de 1993. Disponible en: http:/l www4.congreso.gob.pe/ntley/Imagenes/Constitu/Cons1993.pdf

Paraguay, Ley 4628, que modifica el artículo 229 de la Ley 1160/97, Código Penal, modificado por la Ley 3440/08, 29 de junio de 2012. Disponible en: http://www. bacn.gov.py/MjcxMA==\&ley-n-4628

\section{Documentos en internet}

http://www.parlamento.gub.uy/constituciones/const004.htm 